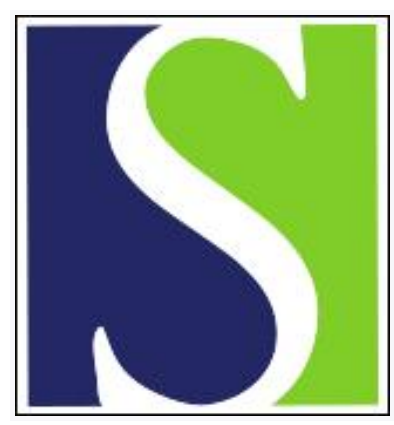

Scand J Work Environ Health 1988;14(6):337-343

https://doi.org/10.5271/sjweh.1909

Issue date: Dec 1988

A review of the epidemiologic literature on magnetic fields and cancer.

by Ahlbom A

Affiliation: Department of Epidemiology, Institute of Environmental Medicine, Karolinska Institute, Stockholm, Sweden.

This article in PubMed: www.ncbi.nlm.nih.gov/pubmed/3062769

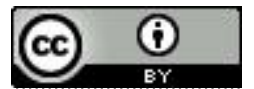




\title{
A review of the epidemiologic literature on magnetic fields and cancer
}

\author{
by Anders Ahlbom, $\mathrm{PhD}^{1}$
}

\begin{abstract}
AHLBOM A. A review of the epidemiologic literature on magnetic fields and cancer. Scand $J$ Work Environ Health 14 (1988) 337-343. Since 1979 several studies have been published that suggest that residential exposure to electromagnetic fields could increase the risk of childhood cancer. Such studies have also been published for adults. In addition there are several studies suggesting that people in "electrical" occupations are at an increased risk of cancer. The objective of this review was to determine whether the role of electromagnetic fields in the origin of cancer can be established from the epidemiologic literature. Several of the studies suffer from methodological or other shortcomings, but it is not clear whether these problems are likely to explain the results. No conclusion can be drawn about the role of electromagnetic fields in the origin of cancer on the basis of current data. The existing literature, however, strongly suggests that research in this area should be pursued.
\end{abstract}

Key terms: electromagnetic fields, epidemiology, occupational exposure, residential exposure.

Since 1979 several studies have appeared that indicate that children living in homes near power lines or other electric transmission facilities or in homes with measured elevated magnetic fields have an increased risk of cancer. There are also studies on adults showing the same phenomenon. Several studies have also shown that "electrical workers" might be at increased risk. The objective of the present article was to review this body of epidemiologic literature to determine whether magnetic fields have an etiologic role in the development of cancer in humans. The studies on occupational exposure have been reviewed thoroughly by others ( 7 , 23). The emphasis, therefore, is on a critical review of the studies based on residential exposure.

\section{Residential exposure}

Currently, information is available from nine studies based on residential exposure $(5,9,14,18,24,25,31$, $33,35)$. A summary of some of the characteristics of the nine studies is given in table 1 .

A review of these studies must emphasize the potential systematic errors that might be present due to the design or conduct of the investigations. It is essential, therefore, to recognize the two possible effects that a systematic error can have, ie, they can (i) give rise to a spurious effect (ie, make a study show an effect that does not exist in reality) and (ii) mask a true effect so that it does not appear as an effect in the study. An investigation showing a low relative risk should not be

\footnotetext{
1 Department of Epidemiology, Institute of Environmental Medicine, Karolinska Institute, Stockholm, Sweden.
}

Reprint requests to: Professor A Ahlbom, Department of Epidemiology, Institute of Environmental Medicine, Box 60208, S-104 01 Stockholm, Sweden. criticized on the basis of systematic errors of the first type; similarly, a study showing an elevated relative risk should not be criticized on the basis of systematic errors of the second type.

Research in this area has frequently been criticized for using methods too crude for exposure assessment. Basically, the following three approaches have been employed: (i) identification and coding of nearby wires, transformers and substations, in some instances combined with a calculation of the resulting magnetic field; (ii) actual field measurements; and (iii) identification of nearby transmission facilities and measurements of the distance to the home. For information on the approach used in each of the studies, refer to table 1.

The first approach, wire coding, has been criticized for two reasons. (See references, eg, 3, 17). First, wire coding does not take into account magnetic fields generated by sources other than the transmission facilities, such as unbalanced return currents or currents used for appliances. Second, it has been claimed that the wire coding systems are much too simplistic and thus generate results with poor correlations to the actual fields generated by the power lines or by other transmission facilities. However, the two latest studies employed both wire coding and actual field measurements and, thus, produced enough information to allow for a comparison of the two methods with respect to exposure assessment $(24,25)$. This comparison showed that there was indeed room for a refinement of the original wire coding method, and such an attempt was included in one of the studies (25). Nevertheless, it was demonstrated that the original wire coding scheme did predict the measured field so that, for instance, the median of the measured fields increased monotonically with the exposure categories as derived from the wire coding (22). 
Table 1. Characteristics of studies on residential exposure to electromagnetic fields and cancer.

\begin{tabular}{|c|c|c|c|c|c|}
\hline Study & $\begin{array}{l}\text { Study } \\
\text { design }\end{array}$ & $\begin{array}{l}\text { Type of } \\
\text { cancer } \\
\text { diagnosed }\end{array}$ & Location & $\begin{array}{l}\text { Exposure } \\
\text { assessment }\end{array}$ & $\begin{array}{c}\text { Number of } \\
\text { eligible } \\
\text { cases }\end{array}$ \\
\hline \multicolumn{6}{|l|}{ Childhood cancer } \\
\hline Wertheimer \& Leeper (33) & $\begin{array}{l}\text { Case- } \\
\text { referent }\end{array}$ & All & $\begin{array}{l}\text { Colorado, } \\
\text { United States }\end{array}$ & Wire coding & 344 \\
\hline Fulton et al (9) & $\begin{array}{l}\text { Case- } \\
\text { referent }\end{array}$ & Leukemia & $\begin{array}{l}\text { Rhode Island, } \\
\text { United States }\end{array}$ & Wire coding & 119 \\
\hline Myers et al (18) & $\begin{array}{l}\text { Case- } \\
\text { referent }\end{array}$ & All & $\begin{array}{l}\text { Yorkshire, } \\
\text { United Kingdom }\end{array}$ & $\begin{array}{l}\text { Calculated } \\
\text { fields }\end{array}$ & 376 \\
\hline Tomenius (31) & $\begin{array}{l}\text { Case- } \\
\text { referent }\end{array}$ & All & $\begin{array}{l}\text { Stockholm, } \\
\text { Sweden }\end{array}$ & $\begin{array}{l}\text { Measured fields, } \\
\text { distance }\end{array}$ & 716 \\
\hline Savitz et al (24) & $\begin{array}{l}\text { Case- } \\
\text { referent }\end{array}$ & All & $\begin{array}{l}\text { Colorado, } \\
\text { United States }\end{array}$ & $\begin{array}{l}\text { Measured fields, } \\
\text { wire coding }\end{array}$ & 356 \\
\hline \multicolumn{6}{|l|}{ Adult cancer } \\
\hline Wertheimer \& Leeper (35) & $\begin{array}{l}\text { Case- } \\
\text { referent }\end{array}$ & All & $\begin{array}{l}\text { Colorado, } \\
\text { United States }\end{array}$ & Wire coding & 1179 \\
\hline Coleman et al (5) & $\begin{array}{l}\text { Case- } \\
\text { referent }\end{array}$ & Leukemia & $\begin{array}{l}\text { London, } \\
\text { United Kingdom }\end{array}$ & Distance & 811 \\
\hline McDowall (14) & Cohort & All & $\begin{array}{l}\text { East Anglia, } \\
\text { United Kingdom }\end{array}$ & Distance & 213 \\
\hline Severson et al (25) & $\begin{array}{l}\text { Case- } \\
\text { referent }\end{array}$ & Leukemia & $\begin{array}{l}\text { Seattle, } \\
\text { United States }\end{array}$ & $\begin{array}{l}\text { Measured fields, } \\
\text { wire coding }\end{array}$ & 114 \\
\hline
\end{tabular}

Furthermore, a general result of epidemiologic theory is relevant in this instance. When the limitations of exposure assessment affect cases and noncases similarly, ie, with the same sensitivity and specificity, the estimated relative risk will be biased towards unity. (See, eg, reference 2.) This phenomenon is commonly referred to as nondifferential misclassification. In effect, as long as the wire coding system is applied in the same way to cases and noncases, any exposure misclassification can only mask a true effect; it cannot give rise to a spurious effect. Therefore, limitations of the ability of the wire coding scheme to predict magnetic fields does not seem to be of relevance in the context of explaining the findings of the studies indicating an association between magnetic fields and cancer.

The second approach, actual measurements, has its drawbacks because of the variation over time of the magnetic fields, which in turn is a consequence of the variation in the use of appliances, heating, etc. It appears that both short- and long-term field variations might be considerable. This possibility also exists for variations between different locations within the homes; fields increase in the proximity of appliances but level off rapidly as the distance from the appliances increases. In general, however, this phenomenon again tends to result in an exposure misclassification with the ability of masking a true effect but not of generating a spurious one.

The third approach, using the distance between a home and an identified transmission or distribution facility as a proxy for exposure, may be viewed simply as a crude variant of wire coding using only one category for all kinds of transmission facilities.

In addition to the aforementioned problem, Wertheimer \& Leeper, in their two studies $(33,35)$, used a design for data collection whereby the person who drew the map to be used for the wire coding knew whether the house belonged to a case or a referent. This potential source of bias, unlike the one discussed earlier, could give rise to spurious effects. The authors have made some attempts to evaluate the magnitude of this possible bias, but the importance remains unclear. One common feature of case-referent studies is, however, that interviews cannot be performed blindly, and exposure assessment in a case-referent study is therefore generally performed with the interviewer being aware of the case-referent status of the subjects. To date, only little is known as to the importance of this possible systematic error, usually referred to as recall bias (19). Therefore, it does not seem justified to discard the Wertheimer \& Leeper studies because of lack of blindness in the exposure assessment, although differential exposure misclassification does remain a concern.

In several of the investigations, the homes, rather than the individuals, constituted the units of study ( 9 , $31,33,35)$. These investigations were all case-referent in nature; indeed, in a cohort study it would be obvious that, if homes were used as study units, everyone who had lived in more than one home would, mistakenly, be counted more than once. Given the rationale behind the case-referent design, the use of homes rather than individuals is no more justified in such studies than in cohort investigations (2). The question remains; however, of the impact of using homes rather than individuals on the results. It seems reasonable to assume that the point estimates of the relative risks are not biased in any predictable direction, but that the confidence limits are tighter than they should be, since the study sizes are apparently too big. Fortunate- 
ly, all reports except one also give sufficient information to allow for the calculation of some individually based results (9).

Only in the two latest studies did the available information allow for control of confounding from factors other than some basic demographic variables $(24$, 25 ). It has been suggested that, for example, a socioeconomic gradient in childhood cancer incidence together with a difference in the socioeconomic distribution between neighborhoods near power lines and other neighborhoods could explain the observed associations. Several other confounders have been proposed as well. Both of the two latest studies included information on major potential confounders, but in neither case did the result change as an effect of attempts to control for confounding from these variables $(24,25)$. According to unpublished results by $\mathrm{Dr}$ Savitz, a control of confounding from traffic density did not affect the results in any significant way either.

The possibility of confounding as an explanation for the results cannot be ruled out, but it seems unlikely that such a confounder would be a previously known risk factor. Indeed, for the cancers considered in this context, the etiology is basically unknown, and it is questionable whether any of the few known risk factors is likely to be associated with the exposure in ques-

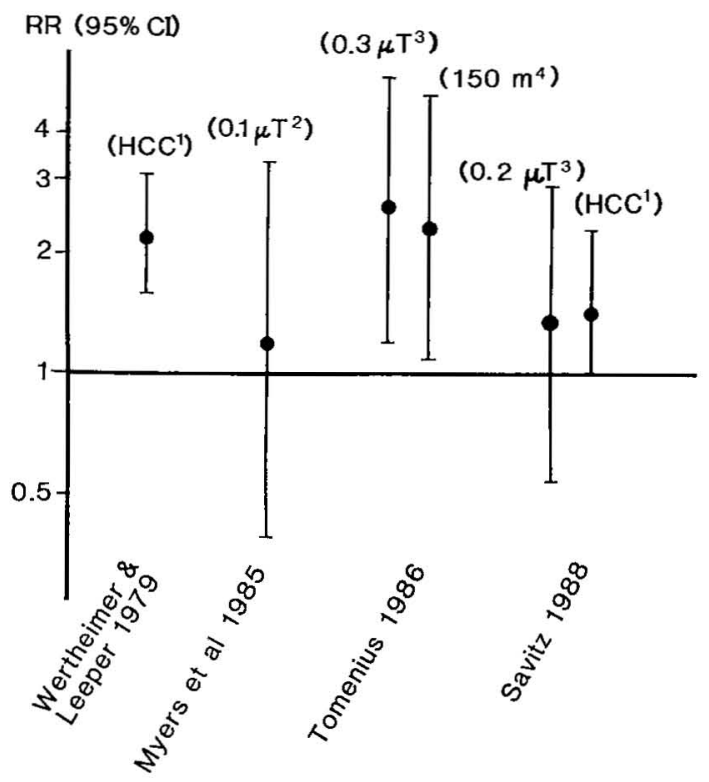

Figure 1. Results of four studies on all cases of childhood cancer and residential exposure to electromagnetic fields. $(1=$ high current configuration (HCC) according to wire code, $2=$ calculated field, ${ }^{3}=$ measured field, ${ }^{4}=$ distance to $220-\mathrm{kV}$ line, $\mathrm{RR}=$ relative risk) tion. One might, indeed, argue that the validity of a study should not be criticized on the bases of confounding unless a conceivable confounder can be shown to exist. This argument implies, of course, that the interpretation of existing data might change as a consequence of increasing knowledge.

Figures 1 through 4 summarize the results from the nine reported studies. For all the studies, the relative risks and $95 \%$ confidence limits are given for certain exposure categorizations. For some of the studies, results based on more than one such categorization are given. In studies in which the relative risk or the confidence interval was not given, they have been calculated from absolute numbers presented in the reports by use of the test-based principle (2). The open-ended bars indicate that the calculations were based on residences rather than individuals. (See the preceding text.)

Figure 1 summarizes the results from available studies for all childhood cancers together, regardless of site or histopathology. In most instances, the precision is limited, as shown by the wide confidence limits, and the range of the point estimates is wide, but none of the estimates is below unity. In fact, given the different study designs, time periods, and locales, the findings of the different studies do appear to be rather consistent.

RR $(95 \% \mathrm{CI})$

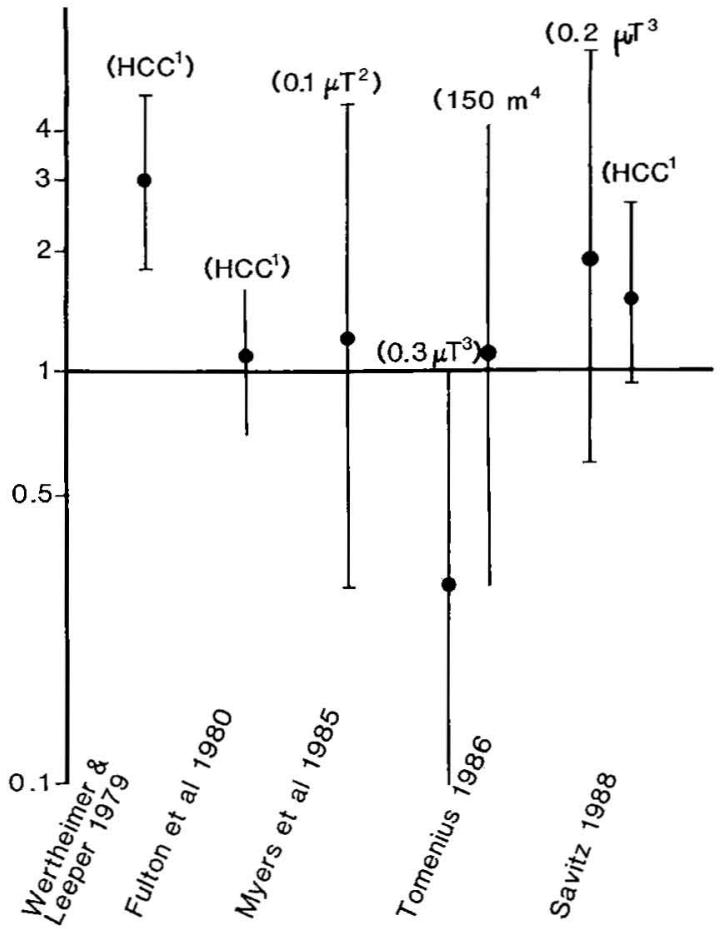

Figure 2. Results of five studies on cases of childhood leukemia and residential exposure to electromagnetic fields. The open-ended bars indicate that the calculations have been based on homes rather than individuals. ${ }^{1}=$ high current configuration ( $\mathrm{HCC}$ ) according to wire code, ${ }^{2}=$ calculated field, $3=$ measured field, ${ }^{4}=$ distance to $220-k V$ line, $R R=$ relative risk) 


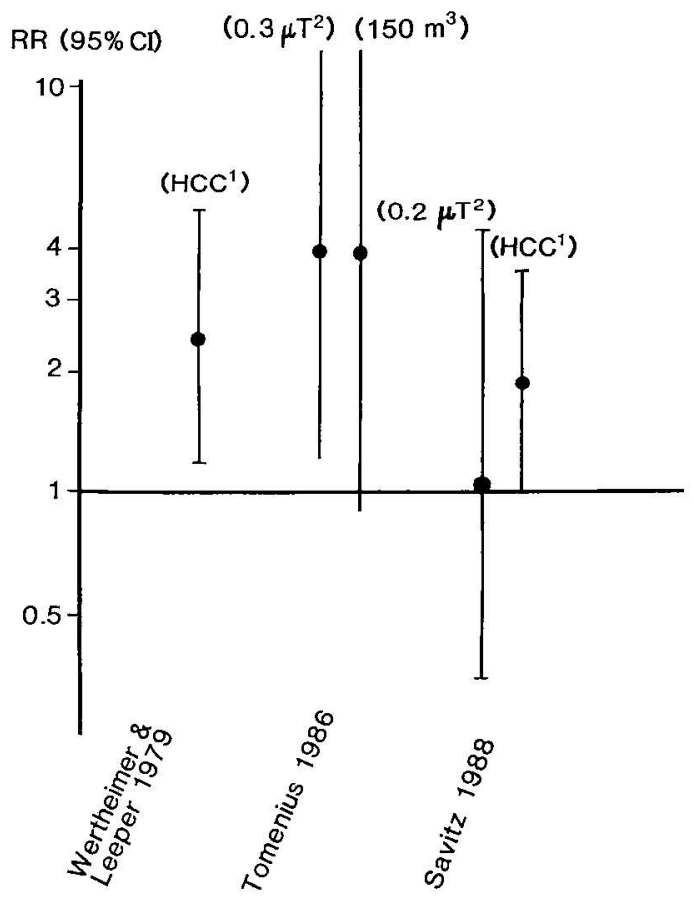

Figure 3. Results of three studies on cases of central nervous system tumors among children and residential exposure to electromagnetic fields. The open-ended bars indicate that the calculations have been based on homes rather than individuals. $\left({ }^{1}=\right.$ high current configuration $(\mathrm{HCC})$ according to wire code, ${ }^{2}=$ measured field, ${ }^{3}=$ distance to $220-\mathrm{kV}$ line, $\mathrm{RR}=$ relative risk)

For childhood leukemia and its smaller numbers, the randomness is more predominant, and the findings are less consistent, as seen in figure 2 . The study by Fulton et al (9) gave a point estimate very close to unity, and the study by Tomenius (31) even indicates a preventive effect.

The findings concerning childhood tumors of the central nervous system are summarized in figure 3. Only three studies provide information on these tumors, and the numbers of cases are small. Nevertheless, all three studies indicate elevations in relative risk.

For adult cancers (figure 4) only two of the studies indicate an effect, and one of them has a wide confidence interval. There is little evidence of an effect when these studies are combined.

Some of the studies deserve further comment. The Wertheimer \& Leeper study of childhood cancer (33) was the investigation which triggered interest in this area of research. Their study may be justifiably criticized for the use of homes rather than individuals, for crude exposure assessment, and for the lack of appropriate analyses. No one, however, has been able to point out a flaw in the study which is likely to explain the findings. One major difficulty with this study is the poor organization of the report, which prevents a detailed review of design, selection, measurements, and analysis. One observation is the exceptionally high degree of internal consistency between different results

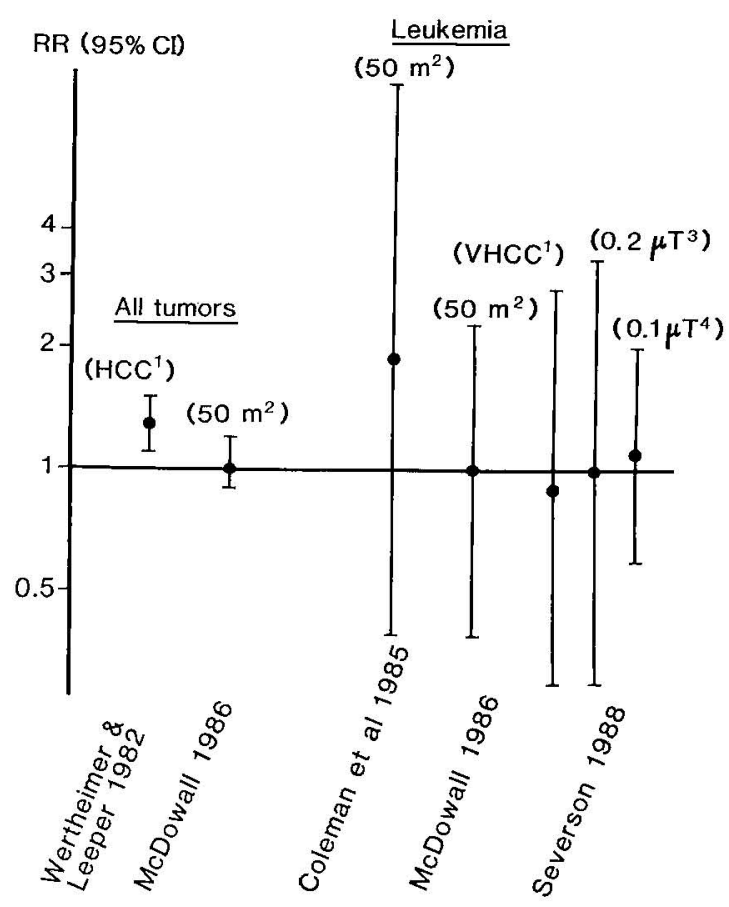

Figure 4. Results of four studies on all adult tumors and cases of adult leukemia and residential exposure to electromagnetic fields. $\left({ }^{1}=\right.$ high (or very high) current configuration according to wire code ${ }^{2}=$ distance to electrical transmission facility, ${ }^{3}=$ measured field, ${ }^{4}=$ calculated field, $R R=$ relative risk)

in the report. This consistency rules out the possibility of chance as an explanation.

The study by Fulton et al (9) specifically addressed childhood leukemia and resulted in a relative risk near unity, although the relative risk was not calculated in the report. It has been criticized for the selection of referents and also for the use of the wire coding system, developed for the Denver area, without differences in the power distribution systems being taken into account (34). These alleged difficulties in the study could mask a real effect.

The first childhood cancer study with actual measurements in this area of research was the one by Tomenius (31); it was done in Stockholm, Sweden. This study may be criticized for reasons similar to those stated for the Wertheimer \& Leeper study (33), but again no one has been able to point out flaws which are likely to explain the findings. A closer look at the results reveals certain inconsistencies. For example, those people living within $200 \mathrm{~m}$ of a $220-\mathrm{kV}$ line have a higher risk of cancer when the magnetic field is below $0.3 \mu \mathrm{T}$ than when it is above this value.

The most recent of the childhood cancer studies is that by Savitz et al (24). The purpose was to repeat the Wertheimer \& Leeper investigation (33) with certain refinements, and this study was also dore in Denver, Colorado, in the United States. It is of major interest since it was done with up-to-date methodology 
and under the supervision of a panel of independent experts and since it supported the major findings of the previous studies (1). All the exposure assessments were made without knowledge of whether a particular residence was a case or a reference home. The measurements were taken under high-power conditions, with lights and appliances turned on, and under lowpower conditions, with as much as possible of the electricity in the houses turned off. The purpose of the measurement under low-power conditions was to determine the external contribution to the magnetic field in the house.

In addition it is also important to note that the study of Savitz et al (24) was designed as a population-based case-referent study in the sense that the eligible cases included all cases in the defined population and that the reference group was selected according to a principle ensuring that it can be considered a random sample of the population. Therefore, except for problems due to registration, location, and nonresponse, the validity of the case series and the reference series does not need to be questioned.

On the other hand, one major difficulty with the study is the limited response rate. Mainly, since a considerable proportion of the families had moved after the time of diagnosis, it was not possible to obtain measurements from more than $36 \%$ of the case homes. On the other hand, wire coding could be done without access to the house, and such codes were obtained for $90 \%$ of the case homes and $93 \%$ of the reference homes. Of the cases, $71 \%$ of the persons concerned were interviewed, while the corresponding rate for the referents was $80 \%$.

There was no overlapping between the Wertheimer \& Leeper study (33) and the Savitz et al study (24) with respect to either study period or the subjects in the studies.

Low-power magnetic field measurements at the time of the diagnosis and wire codes showed some association with cancer risk, and the association was the most pronounced for leukemia.

The wire coding categorization yielded higher relative risk estimates than did the actual measurements. One explanation for this result might be that the wire coding, after all, is a better predictor of past exposure, exposure categorization based on spot measurements being inevitably susceptible to nondifferential misclassification due to field variations over time. High-power magnetic fields or electric fields did not show any association with cancer incidence, nor did any exposure characterization at the time of birth. The fact that only exposure near the time of diagnosis showed an association with the disease could indicate that the magnetic field is, if anything, a late-acting cause, ie, a promotor.

As for the adult cancer studies, the Wertheimer \& Leeper study (35) was basically designed as their childhood cancer study (33), and it shares the merits and problems of that study. The main focus of the analy- sis of this study was on total cancer, and the total number of cases was large enough to provide a precise estimate. It is worth noting that leukemia was not among the cancer sites contributing to the elevation in risk.

Like the Savitz et al study (24), the study by Severson et al (25) was performed according to prevailing epidemiologic standards and under the supervision of the same panel of experts. Although some point estimates are elevated in the report, they are very erratic, and the most reasonable interpretation seems to be that the study does not indicate an association between magnetic fields and leukemia in adults.

\section{Occupational exposure}

Several reports based on census information or some other kind of routinely collected register information have indicated that people employed in "electrical" occupations are at increased risk of developing leukemia. Some of them have appeared as letters to the editor in The Lancet $(6,13,16,21,36)$ and The New England Journal of Medicine $(4,15)$, and others have been published elsewhere $(11,20,30,32)$. The occupations considered "electrical" include a wide variety of occupations, such as telegraph and radio operators, power and telephone linemen, station operators, electrical and electronic engineers, and electronic assemblers.

Due to the nature of the data sources of these reports, the information about the study subjects is limited to basic demographic data and job title. Therefore, little is known about actual exposure to magnetic fields, as well as to possible confounders such as soldering fumes, solvents, and other chemical substances. This lack of data holds true for both the specific individuals included in these studies and the occupational groups as a whole. The wide variety of occupations considered indicates, however, that the nature, in terms of frequency and intensity, of possible magnetic fields must differ considerably between the groups. It is worth noting in this context that, although little is known about occupational exposures to magnetic fields in general, it seems clear that some occupations yield exposure to fields that are orders of magnitude higher than the exposure of other groups or exposure in the residential setting (28).

There are also some case-referent studies on leukemia which have utilized information other than census data and have found a relationship with presumed occupational exposure to magnetic fields $(8,10,27)$. Although none of these studies used actual magnetic field measurements, the exposure information was more specific than in the studies using only job titles, and it was also possible to control for some potential confounding from other risk factors, including other occupational risk factors.

Some studies also exist that show an association between presumed occupational magnetic field ex- 
posure and brain tumors $(12,29)$, and one study found an association between childhood neuroblastoma and presumed parental occupational exposure to magnetic fields (26).

Despite the obvious limitations of these studies and the somewhat erratic findings, it is difficult to avoid the conclusions that there is a certain consistency between the results and that it seems likely that these occupations are in fact at an increased risk of leukemia. It does not seem likely that one single confounder explains the associations for all the involved occupations, but of course it is tenable that different confounders operate and that the explanations differ between the occupations. However, exposure to magnetic fields remains one of the candidates to explain the elevations in cancer risk.

\section{Concluding remarks}

Even before the presentation of the study by Savitz et al (24), available information indicated that children living near power transmission facilities or in homes with elevated magnetic fields might be at increased risk of cancer. However, so many methodological and theoretical concerns were raised against these studies that the findings had to be considered highly uncertain. The results of Savitz et al support, although not strongly, the findings of previous studies. It thereby adds to the credibility of the hypothesis that exposure to magnetic fields might be of importance to the origin of childhood cancer.

The results of studies on adult cancer and residential exposure, when combined, do not provide much evidence for an association with all cancers together or with leukemia, but of course the possibility of such an association is not ruled out. Adults are likely to spend less time at home than children and, therefore, the effects might be more "diluted." Furthermore, the studies on residential exposure should be considered in tandem with the studies on occupational exposure, and when their results are combined, indeed, an association cannot be disproved.

It is not possible, from the available information, to conclude whether or not exposure to magnetic fields increases the risk of cancer. The information does, however, strongly suggest that research in this area should be pursued.

\section{Acknowledgments}

It gives me great pleasure to acknowledge the helpful comments made by Dr D Savitz and Ms M Feychting.

\section{References}

1. Ahlbom A, Albert EN, Fraser-Smith AC, Grodzinsky AJ, Marron MT, Martin AO, Persinger MA, Shelan- ski ML, Wolpow ER. Panel's final report: Biological effects of power line fields. New York state power lines project scientific advisory panel final report. New York State Power Line Project, New York, NY 1987.

2. Ahlbom A, Norell SE. Introduction to modern epidemiology. Epidemiology Resources Inc, Chestnut Hill, MA 1984.

3. Bryan FA Jr. Electrical wiring configurations and childhood leukemia in Rhode Island. Am J Epidemiol 112 (1980) 419-420. (Letter to the editor).

4. Calle EE, Savitz DA. Leukemia in occupational groups with presumed exposure to electrical and magnetic fields. N Engl J Med 313 (1985) 1476-1477. (Letter to the editor).

5. Coleman M, Bell CMJ, Taylor HL, Thornton-Jones $\mathbf{H}$. Leukaemia and electromagnetic fields: A case-control study. Paper presented at the International Conference in Electric and Magnetic Fields in Medicine and Biology. London, December 1985.

6. Coleman M, Bell J, Skeet R. Leukaemia incidence in electrical workers. Lancet 1 (1983) 982-983. (Letter to the editor).

7. Coleman M, Beral V. A review of epidemiological studies of the health effects of living near or working with electricity generation and transmission equipment. Int J Epidemiol 17 (1988) $1-13$.

8. Flodin U, Fredriksson M, Axelson O, Persson B, Hardell L. Background radiation, electrical work, and some other exposures associated with acute myeloid leukemia in a case-referent study. Arch Environ Health 41 (1986) $77-84$.

9. Fulton JP, Cobb S, Preble L, Leone L, Forman E. Electrical wiring configurations and childhood leukemia in Rhode Island. Am J Epidemiol 111 (1980) 292-296.

10. Gilman PA, Ames RG, McCawley MA. Leukemia risk among US white male coal miners: A case-control study. J Occup Med 27 (1985) 669-671.

11. Howe G, Lindsay JP. A follow-up study of a ten-percent sample of the Canadian labor force: I Cancer mortality in males, 1965-73. J Natl Cancer Inst 70 (1983) $37-44$.

12. Lin RS, Dischinger PC, Conde J, Farrell KP. Occupational exposure to electromagnetic fields and the occurrence of brain tumors: An analysis of possible associations. J Occup Med 27 (1985) 413-419.

13. McDowall ME. Leukaemia mortality in electrical workers in England and Wales. Lancet 1 (1983) 246. (Letter to the editor).

14. McDowall ME. Mortality of persons resident in the vicinity of electricity transmission facilities. $\mathrm{Br} \mathrm{J}$ Cancer 53 (1986) $271-279$.

15. Milham S Jr. Mortality from leukemia in workers exposed to electrical and magnetic fields. N Engl J Med 307 (1982) 249. (Letter to the editor).

16. Milham S Jr. Silent keys: Leukaemia mortality in amateur radio operators. Lancet 1 (1985) 812. (Letter to the editor).

17. Miller MW. Electrical wiring configurations and childhood cancer. Am J Epidemiol 112 (1980) 165-166. (Letter to the editor).

18. Myers A, Cartwright RA, Bonnell JA, Male JC, Cartwright SC. Overhead power lines and childhood cancer. Paper presented at the International Conference in Electric and Magnetic Fields in Medicine and Biology, London, December 1985.

19. Norell SE, Ahlbom A. Hospital versus population referents in two case-referent studies. Scand J Work Environ Health 13 (1987) 62-66.

20. Olin R, Vågerö D, Ahlbom A. Mortality experience of electrical engineers. Br J Ind Med 42 (1985) 211-216.

21. Pearce NE, Sheppard RA, Howard JK, Fraser J, Lilley BM. Leukaemia in electrical workers in New Zealand. Lancet 1 (1985) $811-812$. (Letter to the editor). 
22. Savitz DA. Case-control study of childhood cancer and residential exposure to electric and magnetic fields: Contractor's final report. New York State Power Lines Project, New York, NY 1987.

23. Savitz DA, Calle EE. Leukemia and occupational exposure to electromagnetic fields: Review of epidemiologic surveys. J Occup Med 29 (1987) 47-51.

24. Savitz DA, Wachtel H, Barnes FA, John EM, Tvrdik JG. Case-control study of childhood cancer and exposure to 60-hertz electric and magnetic fields. Am J Epidemiol 128 (1988) 10-20.

25. Severson RK, Stevens RG, Kaune WT. Acute nonlympho-cytic leukemia and residential exposure to power frequency magnetic fields. Am J Epidemiol 128 (1988) $21-38$.

26. Spitz MR, Johnsson CC. Neuroblastoma and paternal occupation: A case-control analysis. Am J Epidemiol 121 (1985) 924-929.

27. Stern FB, Waxweiler RA, Beaumont JJ, Lee ST, Rinsky RA, Zumwalde RD, Halperin WE, Bierbaum PJ, Landrigan PJ, Murray WE Jr. A case-control study of leukemia at a naval nuclear shipyard. Am J Epidemiol 123 (1986) $980-992$.

28. Stuchly MA, Hansson Mild K. Environmental and occupational exposure to electromagnetic fields. IEEE Eng Med Biol Mag (1987) 15-17.

29. Thomas TL, Stolley PD, Stemhagen A, Fontham ETH, Bleecker ML, Stewart PA, Hoover RN. Brain tumor mortality risk among men with electrical and electronics jobs: A case-control study. J Natl Cancer Inst 79 (1987) 233-238.

30. Törnqvist S, Norell S, Ahlbom A, Knave B. Cancer in the electric power industry. Br J Ind Med 43 (1986) $212-213$.

31. Tomenius L. $50-\mathrm{Hz}$ electromagnetic environment and the incidence of childhood tumors in Stockholm County. Bioelectromagnetics 7 (1986) 191-207.

32. Vågerö D, Ahlbom A, Olin R, Sahlsten S. Cancer morbidity among workers in the telecommunications industry. Br J Ind Med 42 (1985) 191-195.

33. Wertheimer $\mathrm{N}$, Leeper E. Electrical wiring configurations and childhood cancer. Am J Epidemiol 109 (1979) $273-284$.

34. Wertheimer N, Leeper E. Electrical wiring configurations and childhood leukemia in Rhode Island. Am J Epidemiol 111 (1980) 461-462. (Letter to the editor).

35. Wertheimer N, Leeper E. Adult cancer related to electrical wires near the home. Int J Epidemiol 11 (1982) $345-355$.

36. Wright WE, Peters JM, Mack TM. Leukaemia in workers exposed to electrical and magnetic fields. Lancet 2 (1982) 1160-1161. (Letter to the editor).

Received for publication: 23 May 1988 